\title{
Castration Modulates Singing Patterns and Electrophysiological Properties of RA Projection Neurons in Adult Male Zebra Finches
}

Castration can change levels of plasma testosterone. Androgens such as testosterone play an important role in stabilizing birdsong. The robust nucleus of the arcopallium (RA) is an important premotor nucleus critical for singing. In this study, we investigated the effect of castration on singing patterns and electrophysiological properties of projection neurons (PNs) in the RA of adult male zebra finches.Adult male zebra finches were castrated and the changes in bird song assessed. We also recorded the electrophysiological changes from RA PNs using patch clamp recording. We found that the plasma levels of testosterone were significantly decreased, song syllable's entropy was increased and the similarity of motif was decreased after castration. Spontaneous and evoked firing rates, membrane time constants, and membrane capacitance of RA PNs in the castration group were lower than those of the control and the sham groups. Afterhyperpolarization AHP time to peak of spontaneous action potential (AP) was prolonged after castration. These findings suggest that castration decreases song stereotypy and excitability of RA PNs in male zebra finches. 


\section{Castration Modulates Singing Patterns and Electrophysiological Properties of RA}

3 Castration can change levels of plasma testosterone. Androgens such as testosterone play an

4 important role in stabilizing birdsong. The robust nucleus of the arcopallium (RA) is an important

5 premotor nucleus critical for singing. In this study, we investigated the effect of castration on

6 singing patterns and electrophysiological properties of projection neurons (PNs) in the RA of

7 adult male zebra finches.

8 Adult male zebra finches were castrated and the changes of song were assessed. We also recorded

9 the electrophysiological changes of RA PNs using patch clamp recording. We found that the

10 plasma levels of testosterone were significantly declined, song syllable's entropy was increased

11 and the similarity of motif was decreased after castration. Spontaneous and evoked firing rates,

12 membrane time constants, and membrane capacitance of RA PNs in the castration group were

13 lower than those in the control and the sham groups. Afterhyperpolarization $\square \mathrm{AHP} \square$ time to peak of

14 spontaneous action potential (AP) was prolonged after castration. These findings suggest that

15 castration decreases song stereotypy and excitability of RA PNs in male zebra finches.

16

17

18

19 
20 Songhua Wang, Congshu Liao, Fengling Li, Shaoyi Liu, Wei Meng, Dongfeng Li

22 Corresponding author: Dongfeng Li.

23 School of Life Science, South China Normal University, Key Laboratory of Ecology and Environmental

24 Science in Higher Education of Guangdong Province, Guangzhou 510631, China

25 Tel.: +86 20 8521372, E-mail: dfliswx@126.com

\section{INTRODUCTION}

27 Steroid sex hormones change oscines song behavior and modulate the underlying neural substrates in 28 adulthood. Androgens, particularly testosterone, play important roles in stabilizing birdsong. For example, 29 testosterone can increase the stability of song (Meitzen et al. 2009a; Sizemore \& Perkel 2011), the size of song 30 nuclei (Brenowitz et al. 1998; Brenowitz et al. 1991; Dloniak \& Deviche 2001; Hall \& Macdougall-Shackleton 31 2012; Meitzen \& Thompson 2008), the expression of androgen receptor mRNA (Fraley et al. 2010; Wacker et

32 al. 2010) and the excitability in song-control neurons (Meitzen et al. 2007a; Meitzen et al. 2007b) in seasonally

33 breeding songbirds.

34 The robust nucleus of the arcopallium (RA) is a crucial nucleus in the song control system, receiving

35 synaptic input from both the HVC (used as a proper name) and lateral magnocellular nucleus of the anterior

36 nidopallium (LMAN) (Kao et al. 2008; Olveczky et al. 2005; Wild 1993). The HVC-RA pathway produces a

37 stereotyped pattern contributing to stable song, and while the LMAN-RA pathway fires when male birds sing to

38 female birds, LMAN neurons exhibit reliable firing of single spikes precisely locked to song. Thus, the LMAN

39 may act as a source of variability (Nottebohm 2005). The axons of projection neurons (PNs) in the ventral RA

40 project topographically onto the hypoglossal motor nucleus (nXIIts) that innervates the syrinx, and the axons of

41 PNs in the dorsal RA project to the areas in the lateral medulla that control respiration (Vicario 1994; Xie et al. 
42 2010). Lesion of the RA causes severe song deficits (Nottebohm et al. 1976). Moreover, RA activity is

43 significantly correlated with variations in the spectral entropy of syllables (Sober et al. 2008), and RA shows

44 accurately timed and structured bursts of activity that are associated with specific syllables (Yu \& Margoliash 45 1996).

46 Testosterone and estradiol act on brain areas to affect a multitude of attributes, including the rate of

47 neuronal survival and excitability in song-control neurons (Meitzen et al. 2007a; Meitzen \& Thompson 2008;

48 Thompson 2011; Thompson \& Brenowitz 2005; Thompson \& Brenowitz 2010).The HVC and area X express

49 androgen/estrogen receptors, however, other nuclei of the song control system only express androgen

50 receptors (Meitzen et al. 2009b). Androgen and estrogen receptors in the HVC can be co-activated to drive the

51 change of the excitability of RA PNs, thus testosterone and estradiol can act transsynaptically within the HVC

52 and RA to regulate neuronal phenotype (Meitzen et al. 2007a).Recent studies have shown that testosterone and

53 photoperiod affect the excitability of RA PNs in seasonally breeding songbirds that undergo major hormonal

54 shifts as a result of photoperiod, but have no effect on the electrophysiological properties of HVC

55 neurons(Meitzen et al. 2009b). Zebra finches are opportunistic breeders rather than seasonal breeders (Prior et

56 al. 2013). Castration of adult male zebra finches declines testosterone levels in plasma (Adkins-Regan et al.

57 1990), reduces their singing rate but has no effect on the structure of song (Arnold 1975). Castration and

58 antisteroid treatment extremely disrupts the stereotypy and acoustic quality of individual note production, as

59 well as stereotypy of the temporal structure of the song phrase in juvenile male zebra finches, but exerts no

60 deleterious effects on the quality of song behavior in adulthood (Bottjer \& Hewer 1992).In adult male zebra

61 finches, high levels of testosterone decrease the frequency of syllable in song and reduce the potential for

62 vocal plasticity (Cynx et al. 2005; Williams et al. 2003), we predicted that the decline of testosterones levels

63 may induce the plastic song. RA is a crucial nucleus for singing pattern. It is unknown whether the change in 
64 singing pattern is accompanied by changes in electrophysiological properties of RA in adult male zebra

65 finches. To address these issues, we examined the effect of castration on singing patterns and

66 electrophysiological properties of RA PNs in adult male zebra finches. Our data showed that castration

67 decreases song stereotypy and excitability of RA PNs.

68

69 MATERIALS AND METHODS

70

71

72

73

74

75

76

77

78

testicles were removed with ophthalmic forceps. The sham group underwent the same surgery without

\section{Animals and experimental treatments}

A total of 27 adult male zebra finches (Taeniopygia guttata) $(>120$ days old) obtained from a commercial breeder were used in this study. All experiments were carried out in accordance with the University and China animal guidelines. The care and use of animals for this study was approved by the Institutional Animal Care and Use Committee at South China Normal University and in accordance with National Institutes of Health guidelines (scnu20070033). Birds were housed in stainless steel cages $(23.5 \times 22.5 \times 27.5 \mathrm{~cm})$, and each of the cages contained a pair of male and female birds, which were provided with ad libitum food and water and were kept in 14:10 h light/dark cycles. All birds were divided into three main experimental groups: castration group ( $n=11$ birds), control group ( $n=12$ birds), and sham group ( $n=4$ birds).

Before castration, the songs of all birds were recorded in the presence of adult female birds. Birds were then anesthetized with $10 \%$ chloral hydrate $(0.02 \mathrm{~mL} / 10 \mathrm{~g})$. A small incision was made on the lateral wall of the body cavity between the last two ribs just ventral to the ventral margin of the kidney (Arnold 1975). The removing the testicles. The control group did not receive surgery.

\section{Song recording}


85 The song recording room $(2.5 \times 2 \times 2.5 \mathrm{~m})$ contained TAKSTAR directional microphones (Guangdong

86 Victory Electronics Co.Ltd., Guangzhou, China; frequency range: 50-20000 Hz) and a glass window $(85 \times 65$

$87 \mathrm{~cm})$. Birds in the song recording room could see the other birds from the glass window. When the songs were

88 recorded, the male bird was placed in a cage in the song recording room near the glass window, while the

89 female bird was placed in a cage near the glass window outside of the song recording room, so that the male

90 bird could observe the female bird through the window. On each recording day, every bird was recorded for

91 90-120 min. Songs were recorded between 8:00 a.m and 11:00 a.m. Songs were recorded before the castration

92 and sham operation. When birds produce a stable song, the date defined as 'pre'. The songs were then recorded

93 again at the 30th day after castration and sham operation. The songs of birds in control group also were

94 recorded at 'pre' and 30th day. Song recording was performed using Cool Edit 2000 (Adobe Systems Co., SAN

95 Jose, CA, USA; sampling rate: $44100 \mathrm{~Hz}$; channels: stereo; resolution: 16-bit).

\section{Stereotypy of song}

97 We analyzed song stereotypy by calculating entropy (a measure of randomness, entropy is high when the

98 waveform is random, and low when the waveform is of pure tone) (Meitzen et al. 2009a; Tchernichovski et al.

99 2000)of the longest syllable (the distance-call element, whose structure matched that of distance call and is

100 derived from distance call(Bolhuis 1999)) in the motifs within a record using Sound Analysis Pro 2011

101 (contrast: 0, frequency range: 0-11025 Hz, FFT data window: $10 \mathrm{~ms}$, advance window: $1 \mathrm{~ms}$, contour thresh:

102 10). On each recording day the entropy of 30 syllables in 30 motifs was analyzed. Sixty motifs were used to

103 analyze the percentage similarity (\% similarity) of the motif in the song (Meitzen et al. 2009a; Sizemore \&

104 Perkel 2011). Higher entropy indicates less stereotypy, while higher (\% similarity) indicates more stereotypy.

\section{Slice preparation}

106 At the 30th day after castration, the birds were anesthetized with $10 \%$ chloral hydrate and then rapidly 
decapitated. Brains were dissected into ice-cold, oxygenated $\left(95 \% \mathrm{O}_{2}\right.$ and $\left.5 \% \mathrm{CO}_{2}\right)$ slice solution. Slice

108 solution consisted of $\mathrm{KCl} 5 \mathrm{mM}, \mathrm{NaH}_{2} \mathrm{PO}_{4} \cdot \mathrm{H}_{2} \mathrm{O} 1.26 \mathrm{mM}, \mathrm{MgSO}_{4} \cdot 7 \mathrm{H}_{2} \mathrm{O} 1.3 \mathrm{mM}, \mathrm{NaHCO}_{3} 28 \mathrm{mM}$, glucose 10

$109 \mathrm{mM}$, sucrose $248 \mathrm{mM}$, and $\mathrm{NaCl} 62.5 \mathrm{mM}$ (Bottjer 2005). Coronal brain slices (250-300 $\mu \mathrm{m}$ thick) containing

110 the RA were cut with a vibrating microtome (World Precision Instruments Inc., Sarasota, FL, USA) and

111 collected in artificial cerebrospinal fluid (ACSF) that was warmed to $37^{\circ} \mathrm{C}$. After 30 min the ACSF was cooled

112 to $35^{\circ} \mathrm{C}$, and the slices were allowed to recover in the holding chamber for 1-1.5 h. Standard ACSF consisted

113 of $\mathrm{NaCl} 125 \mathrm{mM}, \mathrm{KCl} 2.5 \mathrm{mM}, \mathrm{NaH}_{2} \mathrm{PO}_{4} \cdot \mathrm{H}_{2} \mathrm{O} 1.27 \mathrm{mM}, \mathrm{MgSO}_{4} \cdot 7 \mathrm{H}_{2} \mathrm{O} 1.2 \mathrm{mM}, \mathrm{NaHCO}_{3} 25 \mathrm{mM}$, glucose 25

$114 \mathrm{mM}$ and $\mathrm{CaCl}_{2} 2.0 \mathrm{mM}$, and the osmolality was adjusted with sucrose to $350 \mathrm{mOsm}$ (Bottjer 2005).

\section{Patch-clamp recording}

116 During the experiments, slices were transferred to a recording chamber where they were continuously

117 perfused with ACSF, saturated with $95 \% \mathrm{O}_{2}$ and $5 \% \mathrm{CO}_{2}$ at room temperature $\left(23-28^{\circ} \mathrm{C}\right)$. RA and the

118 surrounding tissues were observed at low magnification $(50 \times)$ under a BX51WI microscope connected with a

119 DIC-IR video camera (Olympus, Tokyo, Japan). At high magnification (400×), RA neurons were visualized

120 and the recordings were made from RA PNs. Recording pipettes were fabricated from borosilicate glass

121 (Sutter Instrument Co., Novato, CA, USA) using a Flaming-Brown puller (Micropipette Puller P-97; Sutter

122 Instrument Co.), and were filled with the solution containing $\mathrm{KMeSO}_{4} 120 \mathrm{mM}, \mathrm{NaCl} 5 \mathrm{mM}$, $\mathrm{HEPES} 10 \mathrm{mM}$,

123 EGTA $2 \mathrm{mM}, \mathrm{Mg}$-ATP $2 \mathrm{mM}$, and Na-GTP $0.3 \mathrm{mM}$ (pH 7.3-7.4). Osmolality was adjusted with sucrose to

$124340 \mathrm{mOsm}$. The recording pipettes, which had resistances ranging from 4 to $7 \mathrm{M} \Omega$, were positioned using an

125 integrated motorized control system (Sutter Instrument Co.). Signals were amplified with a MultiClamp 700B

126 (Axon Instruments, Sunnyvale, CA, USA). Signals were low-pass filtered at $5 \mathrm{kHz}$, digitized at $10 \mathrm{kHz}$ with

127 DIGIDATA 1322A (Axon Instruments) and acquired using Clampfit 9.2 (Axon Instruments). Tight-seal and

128 whole-cell recordings were obtained using standard techniques. The baseline membrane potential was held at 
$-70 \mathrm{mV}$ during the stimulation protocols. RA PNs were identified by their distinct intrinsic properties as

130 described previously (Spiro et al. 1999).

\section{Electrophysiological data analysis}

132 Clampfit 9.2 and Origin Pro 8.0 (Origin Lab, Northampton, MA, USA) were used for analysis. In

133 measuring spontaneous firing rates in the cell-attached configuration, we analyzed the spike amplitude,

134 waveform, and time derivative to ensure that spike events were single units. We measured spontaneous activity

135 for at least $5 \mathrm{~min}$, and calculated the firing rate by dividing the number of spikes observed by the duration of

136 the recording as reported (Meitzen et al. 2007a; Meitzen et al. 2007b). Action potentials (AP) were detected

137 using the event detection package of the Clampfit 9.2. Spontaneous firing rates were calculated at the beginning

138 of the recording as soon as it stabilized following patch rupture. The AP threshold was detected using a custom

139 algorithm described previously by Baufreton (Baufreton et al. 2005); the afterhyperpolarization (AHP) peak

140 amplitude was the difference between the AP threshold and the most negative voltage reached during the AHP.

141 The AHP time to peak was the time of this minimum minus the time when the membrane potential crossed the

142 AP threshold on descent from the AP peak (Farries et al. 2005). For each neuron, the measurements of five APs

143 were averaged to produce the final AP measurements for that neuron. Evoked firing rates were measured after

144 patch rupture. The evoked firing rate was defined as the number of AP evoked over the duration of the current

145 injection. The slope of the F-I relationship was estimated by linear fitting. Slope parameters were estimated

146 separately for individual neurons and mean slope values were averaged for the whole groups of neurons. Input

147 resistance was estimated by applying small hyperpolarizing current pulses. The membrane time constant was

148 calculated by fitting a single exponential curve to the membrane potential change in response to $-200 \mathrm{pA}$

149 hyperpolarizing pulses. Membrane capacitance was calculated using the following equation: capacitance =

150 membrane time constant/input resistance (Meitzen et al. 2009b). 


\section{Hormone assay}

152 On the day of each electrophysiological recording, carotid artery blood was rapidly collected from each

153 subject before they were decapitated into a heparinized microhematocrit tube and stored on ice until

154 centrifugation (within $1 \mathrm{~h}$ ). The plasma was harvested and stored it at $-80^{\circ} \mathrm{C}$. To measure circulating

155 testosterone levels, enzyme-linked immunosorbant was used in a bird testosterone ELISA kit (IBL, Hamburg,

156 Germany), which contained a substrate standard. The minimum detectable plasma testosterone concentration

157 was $0.12 \mathrm{ng} / \mathrm{mL}$, and the maximum was $7.20 \mathrm{ng} / \mathrm{mL}$. All samples were tested in one single assay.

\section{Statistical analysis}

159 All values are reported as mean \pm SEM. We used two-way repeated measures ANOVA to compare the

160 song data at the 30th day after castration and sham operation with the song data at 'pre'(see the part of song

161 recording), and injected current on the evoked firing rate of RA PNs in the castration group with sham and

162 control groups. We used one-way ANOVA to compare the song data at the 30th day with the song data at 'pre'

163 in the control group. We also used one-way ANOVA to compare all plasma testosterone levels and other

164 electrophysiological data of RA PNs in the castration group with sham and control groups. $P$ values $<0.05$

165 were considered

166 significant.

\section{RESULTS}

168 Plasma testosterone levels

169 In the castration group $(\mathrm{n}=11)$, plasma testosterone levels were lower $(3.91 \pm 0.08 \mathrm{ng} / \mathrm{mL})$ compared with the

170 control group $(\mathrm{n}=12)\left(5.15 \pm 0.08 \mathrm{ng} / \mathrm{mL}, F_{(l, 22)}=150.49, P<0.01\right)$ and the sham group $(\mathrm{n}=4)(5.27 \pm 0.09 \mathrm{ng} / \mathrm{mL}$,

$\left.171 \quad F_{(I, 13)}=98.32, P<0.01\right)$. 


\section{Stereotypy of the song before and after castration}

173 We randomly selected five birds in each of the castration and control groups, respectively, to analyze the

174 stereotypes of their songs, while four birds were analyzed in the sham group. Zebra finch song usually contains

175 motifs. Every motif includes two to eight syllables (Nordeen \& Nordeen 2010). In our experiment, we recorded

176 song motifs from castration (Figure $1 \mathrm{~A}_{1}, \mathrm{~A}_{2}$ ), control and sham (Figure $1 \mathrm{~B}_{1}, \mathrm{~B}_{2}$ ) groups, and analyzed the

177 entropy of syllable and \% similarity of the motif in each group (Figure 2).

178 The longest syllable of motif was first analyzed. In the castration group, the entropy was altered gradually,

179 and entropy was significantly increased from $-3.71 \pm 0.31$ to $-3.31 \pm 0.33\left(F_{(1,58)}=33.61, P<0.01\right)$ at the 30th day

180 after castration (Figure 2A). To test the effect of castration on all syllables in the motif, we analyzed other

181 syllables, as shown in Figure $1 \mathrm{~A}_{1}, \mathrm{~A}_{2}$. The entropy of syllable 'a' in 'pre' was $-2.76 \pm 0.06$, while at the 30 th day

182 after castration the entropy changed to $-2.48 \pm 0.05$. Castration increased the entropy of syllable ' $\mathrm{a}$ '

$183\left(F_{(1,58)}=10.77, P<0.01\right)$. Castration also increased the entropy of other syllables (Figure 1A, B).

184 Next, we analyzed the \% similarity of the motif. Castration significantly decreased the \% similarity of the

185 motif from $93.83 \pm 0.80$ to $87.7 \pm 1.04\left(F_{(1,58)}=201.32, P<0.01\right)$ (Figure 2B). However, in the sham group the

186 entropy of syllables and \% similarity of the motif did not change before and after operation, and were similar to

187 the control group (Figure 2A, B).

\section{Electrophysiological properties of RA PNs}

18921 RA PNs from 11 birds of the castrated group, 23 RA PNs from 12 birds of the control group, and 8 RA

190 PNs from 4 birds of the sham group were recorded.

\section{Castration decreased spontaneous firing rates in the cell-attached configuration}

192 When cells were sealed, many RA PNs were spontaneously active in vitro, as described previously in wild

193 song sparrows (Meitzen et al. 2007b). Castration significantly affected the spontaneous firing rate of RA PNs 
compared with the control group $\left(F_{(1,42)}=7.85, P<0.01\right)$ and the sham group $\left(F_{(l, 19)}=8.41, P<0.01\right)$ (Table 1,

195 Figure 3A-C). The mean firing rate of RA PNs was approximately 1.5 times higher in the control group and

196 sham group than that in the castrated group.

197 Castration decreased spontaneous firing rates in the whole-cell configuration

198 In seasonally breeding songbirds, breeding conditions increase spontaneous firing rates in the whole-cell

199 configuration (Meitzen et al. 2009b). In our experiment, castration significantly decreased spontaneous firing

200 rate of RA PNs compared with the control group $\left(F_{(1,31)}=6.65, P=0.015\right)$ and the sham group $\left(F_{(l, 22)}=8.26\right.$,

$201 P<0.01)$ (Table 1, Figure 3D-F).

202 Castration decreased evoked firing rates

203 AP firing rates evoked by depolarizing current injection were significantly decreased in the castrated group

204 (Figure 4A, B). At the current of $100 \mathrm{pA}$ for $500 \mathrm{~ms}$, the mean number of evoked firing was $13.63 \pm 1.12(\mathrm{n}=15)$

205 in the castrated group, $18.00 \pm 0.72(\mathrm{n}=16)$ in the control group and $17.88 \pm 0.88(\mathrm{n}=8)$ in the sham group.

206 Castration significantly decreased the number of evoked firing compared with the control group $\left(F_{(l, 3 l)}=10.43\right.$,

$207 P<0.01)$ (Figure $4 \mathrm{C}$ ) and the sham group $\left(F_{(1,22)}=5.76, P=0.048\right)$. When the currents were set from 0 to $200 \mathrm{pA}$

208 for $500 \mathrm{~ms}$ at $50 \mathrm{pA}$ steps and $10 \mathrm{~s}$ intervals, castration decreased the mean number of evoked firing,

209 particularly at $50 \mathrm{pA}, 100 \mathrm{pA}, 150 \mathrm{pA}$, and $200 \mathrm{pA}(P<0.01)$. F-I curves were linearized. Castration

210 significantly decreased the slope of F-I curve compared with the control group $\left(F_{(1,3 l)}=21.87, P<0.01\right)$ (Figure

$2114 \mathrm{D})$ and sham group $\left(F_{(1,22)}=27.89, P<0.01\right)$ (Table 1).

212 Castration decreased the membrane time constant and capacitance, but increased AHP time to peak

213 To compare input resistance, currents from -200 to $20 \mathrm{pA}$ for $500 \mathrm{~ms}$ at $10 \mathrm{pA}$ steps and $10 \mathrm{~s}$ intervals were

214 injected. The slope of the I-V curve by linear fit was the input resistance. There was no significant difference

215 between the castrated and control groups. Castration significantly decreased the membrane time constant 
compared with the control group $\left(F_{(l, 29)}=10.62, P<0.01\right)$ (Figure 5A) and the sham group $\left(F_{(I, 2 l)}=12.17\right.$,

$217 P<0.01)$. Castration also decreased membrane capacitance compared with the control group $\left(F_{(1,29)}=6.93\right.$,

$218 P=0.013$ ) (Figure 5B) and the sham group $\left(F_{(1.21)}=8.35, P<0.01\right)$. The intrinsic properties of spontaneous AP

219 were also analyzed. AP threshold, AHP peak amplitude, half-width, and peak amplitude of the castration group

220 were similar to the control and sham groups. However, castration significantly prolonged the AHP time to peak

221 compared with the control group $\left(F_{(I, 29)}=12.76, P<0.01\right)$ (Figure $\left.5 \mathrm{C}, \mathrm{D}\right)$ and the sham group $\left(F_{(I, 2)}=13.32\right.$,

$222 P<0.01)($ Table 1). 
224 In the present study, castration declined plasma testosterone levels in adult male zebra finches, although the

225 decline was not as marked as those previously reported (Adkins-Regan et al. 1990; Dloniak \& Deviche 2001;

226 Luine et al. 1980; Marler et al. 1988; Strand \& Deviche 2007). This difference may be due to residual testicular

227 tissue in our study, the brain also makes steroids (Schlinger \& London 2006; Schlinger \& Remage-Healey

228 2012), or differences between breeding and non-breeding zebra finches.

229 High testosterone levels are associated with song stability, which reduces the potential for vocal plasticity

230 (Williams et al. 2003). We found that castration increased the entropy of syllable and decreased the \% similarity

231 of motif in the songs, suggesting that castration decreased the stability of syllables and songs. Our result

232 supported the effects that were described in William's (Williams et al. 2003). However, our results differ from

233 the report of other previous described, in which castration exerts no effects on the stereotyped songs (Arnold

234 1975; Bottjer \& Hewer 1992). It may be the difference of the software for analyzing birdsong. Like seasonally

235 breeding songbirds, when the testosterone and its metabolite levels are high, the song nuclei and the syringes

236 are fully grown (Brenowitz et al. 1998; Brenowitz et al. 1991; Hall \& Macdougall-Shackleton 2012; Tramontin

237 et al. 2000). Testosterone withdrawal induces the regression in the volume of HVC, RA and Area X (Thompson

238 et al. 2007). The inactivation androgen and estrogen receptors in HVC prevent seasonal-like increases in song

239 stereotypy (Meitzen et al. 2007a; Meitzen \& Thompson 2008). When testosterone levels decline, the expression

240 of androgen receptors decrease in HVC (Fraley et al. 2010). Therefore, lower testosterone levels resulted in less

241 stereotyped songs.

242 It was previously reported that testosterone and its metabolite estradiol can regulate the electrophysiological

243 properties of RA PNs (Meitzen et al. 2007a; Meitzen et al. 2007b; Meitzen et al. 2009b).Castration induced 
244 lower plasma levels of testosterone and its estrogenic and androgenic metabolites. Lower levels of androgens

245 and estrogens act transsynaptically within the HVC affecting the electrophysiological properties of RA PNs

246 (Meitzen et al. 2007a). RA is an important premotor nucleus, and these changes in its intrinsic properties may

247 directly modify the motor control of song production, resulting in changes in song stereotypy. In this study,

248 castration decreased spontaneous and evoked firing rates, as well as the membrane time constant and

249 capacitance, but increased AHP time to peak. These results indicate that castration decreased the excitability of

250 the RA PNs, as previously reported (Meitzen et al. 2009b). Castration decreased the spontaneous firing rates

251 and evoked firing rates, which reduce the ability of RA PNs to produce AP in response to synaptic input,

252 particularly from HVC (Meitzen et al. 2009b). Castration decreased the membrane time constant, which might

253 shorten the time available to integrate synaptic input (Meitzen et al. 2009b). As such, RA PNs slowly integrate

254 relatively sparse inputs from the HVC to produce patterned firing that is closely correlated with song

255 production (Yu \& Margoliash 1996). The decrease in membrane capacitance induced by castration may be

256 related to the decrease of the size of RA PNs (Meitzen et al. 2009b).As previously described, testosterone

257 withdrawal induced the regression in somatic area of RA neuron (Thompson et al. 2007). Castration also

258 increased the AHP time to peak, which may be associated with the suppression of large conductance calcium-

259 activated potassium channels (Bean 2007; Faber \& Sah 2002).

260 The HVC-RA pathway contributes to stable song, while the LMAN-RA pathway contributes to variable

261 song (Kao et al. 2008; Nottebohm 2005; Olveczky et al. 2005). Testosterone-stimulated growth of the HVC is

262 sufficient to induce growth of its efferent nucleus-RA (Brenowitz \& Lent 2002). High testosterone levels

263 increase axonal density in the HVC-RA pathway (De Groof et al. 2008). In our castrated birds, low testosterone

264 levels may decrease axonal density in the HVC-RA pathway. High testosterone levels decrease levels of NR2B

265 mRNA, which is modulatory subunits of N-methyl-D-aspartic acid receptor (NMDAR), within the LMAN and 
the RA (Singh et al. 2003). The LMAN-RA input is largely mediated by the NMDAR (Mooney \& Konishi

1991).In our castrated birds, low testosterone levels may increase the modulation of the LMAN-RA input by

the NMDAR. These effects may produce unstable songs.

Finally, the castration-induced decline in testosterone levels and excitability of the RA PNs may decrease

to the RA. All of these effects would produce less stereotyped songs.

In conclusion, our study revealed that castration decreased song stereotypy and the excitability of RA PNs.

273 The results provide a further understanding of how steroid sex hormones modulate electrophysiological

274 properties to change song behavior.

\section{Competing interests}

276 The authors have declared that they have no conflicts of interests.

\section{Author contributions}

WSH, LCS, LFL, LSY, and MW performed research and analyzed data. LDF designed the study and wrote the manuscript. All authors read and approved the final manuscript.

\section{Acknowledgments}

281 This work was supported by the National Natural Science Foundation of China (31172092).

\section{Author details}

283 School of Life Science, South China Normal University, Key Laboratory of Ecology and Environmental

284 Science in Higher Education of Guangdong Province, Guangzhou 510631, China 


\section{References}

286

Adkins-Regan E, Abdelnabi M, Mobarak M, and Ottinger MA. 1990. Sex steroid levels in developing and adult male and female zebra finches (Poephila guttata). Gen Comp Endocrinol 78:93-109.

Arnold AP. 1975. The effects of castration and androgen replacement on song, courtship, and aggression in zebra finches (Poephila guttata). J Exp Zool 191:309-326.

Baufreton J, Atherton JF, Surmeier DJ, and Bevan MD. 2005. Enhancement of excitatory synaptic integration by GABAergic inhibition in the subthalamic nucleus. J Neurosci 25:8505-8517.

Bean BP. 2007. The action potential in mammalian central neurons. Nat Rev Neurosci 8:451-465.

Bolhuis JJ. 1999. The zebra finch: A synthesis of field and laboratory studies. Quarterly Journal of Experimental Psychology Section B-Comparative and Physiological Psychology 52:90-91.

Bottjer SW. 2005. Silent synapses in a thalamo-cortical circuit necessary for song learning in zebra finches. J Neurophysiol 94:3698-3707.

Bottjer SW, and Hewer SJ. 1992. Castration and antisteroid treatment impair vocal learning in male zebra finches. J Neurobiol 23:337-353.

Brenowitz EA, Baptista LF, Lent K, and Wingfield JC. 1998. Seasonal plasticity of the song control system in wild Nuttall's white-crowned sparrows. J Neurobiol 34:69-82.

Brenowitz EA, and Lent K. 2002. Act locally and think globally: intracerebral testosterone implants induce seasonal-like growth of adult avian song control circuits. Proc Natl Acad Sci U S A 99:1242112426.

Brenowitz EA, Nalls B, Wingfield JC, and Kroodsma DE. 1991. Seasonal changes in avian song nuclei without seasonal changes in song repertoire. $J$ Neurosci 11:1367-1374.

Cynx J, Bean NJ, and Rossman I. 2005. Testosterone implants alter the frequency range of zebra finch songs. Horm Behav 47:446-451.

De Groof G, Verhoye M, Van Meir V, Balthazart J, and Van der Linden A. 2008. Seasonal rewiring of the songbird brain: an in vivo MRI study. Eur J Neurosci 28:2475-2485.

Dloniak SM, and Deviche P. 2001. Effects of testosterone and photoperiodic condition on song production and vocal control region volumes in adult male dark-eyed juncos (Junco hyemalis). Horm Behav 39:95-105.

Faber ES, and Sah P. 2002. Physiological role of calcium-activated potassium currents in the rat lateral amygdala. J Neurosci 22:1618-1628.

Farries MA, Meitzen J, and Perkel DJ. 2005. Electrophysiological properties of neurons in the basal ganglia of the domestic chick: conservation and divergence in the evolution of the avian basal ganglia. J Neurophysiol 94:454-467.

Fraley GS, Steiner RA, Lent KL, and Brenowitz EA. 2010. Seasonal changes in androgen receptor mRNA in the brain of the white-crowned sparrow. Gen Comp Endocrinol 166:66-71.

Hall ZJ, and Macdougall-Shackleton SA. 2012. Influence of testosterone metabolites on song-control system neuroplasticity during photostimulation in adult European starlings (Sturnus vulgaris). PLoS One 7:e40060.

Kao MH, Wright BD, and Doupe AJ. 2008. Neurons in a Forebrain Nucleus Required for Vocal Plasticity Rapidly Switch between Precise Firing and Variable Bursting Depending on Social Context. J Neurosci 28:13232-13247.

Luine V, Nottebohm F, Harding C, and McEwen BS. 1980. Androgen affects cholinergic enzymes in 
syringeal motor neurons and muscle. Brain Res 192:89-107.

Marler P, Peters S, Ball GF, Dufty AM, Jr., and Wingfield JC. 1988. The role of sex steroids in the acquisition and production of birdsong. Nature 336:770-772.

Meitzen J, Moore IT, Lent K, Brenowitz EA, and Perkel DJ. 2007a. Steroid hormones act transsynaptically within the forebrain to regulate neuronal phenotype and song stereotypy. $J$ Neurosci 27:1204512057.

Meitzen J, Perkel DJ, and Brenowitz EA. 2007b. Seasonal changes in intrinsic electrophysiological activity of song control neurons in wild song sparrows. J Comp Physiol A Neuroethol Sens Neural Behav Physiol 193:677-683.

Meitzen J, and Thompson CK. 2008. Seasonal-like growth and regression of the avian song control system: neural and behavioral plasticity in adult male Gambel's white-crowned sparrows. Gen Comp Endocrinol 157:259-265.

Meitzen J, Thompson CK, Choi H, Perkel DJ, and Brenowitz EA. 2009a. Time course of changes in Gambel's white-crowned sparrow song behavior following transitions in breeding condition. Horm Behav 55:217-227.

Meitzen J, Weaver AL, Brenowitz EA, and Perkel DJ. 2009b. Plastic and stable electrophysiological properties of adult avian forebrain song-control neurons across changing breeding conditions. $J$ Neurosci 29:6558-6567.

Mooney R, and Konishi M. 1991. Two distinct inputs to an avian song nucleus activate different glutamate receptor subtypes on individual neurons. Proc Natl Acad Sci U S A 88:4075-4079.

Nordeen KW, and Nordeen EJ. 2010. Deafening-induced vocal deterioration in adult songbirds is reversed by disrupting a basal ganglia-forebrain circuit. J Neurosci 30:7392-7400.

Nottebohm F. 2005. The neural basis of birdsong. PLoS Biol 3:e164.

Nottebohm F, Stokes TM, and Leonard CM. 1976. Central control of song in the canary, Serinus canarius. J Comp Neurol 165:457-486.

Olveczky BP, Andalman AS, and Fee MS. 2005. Vocal experimentation in the juvenile songbird requires a basal ganglia circuit. PLOS Biol 3:e153.

Prior NH, Heimovics SA, and Soma KK. 2013. Effects of water restriction on reproductive physiology and affiliative behavior in an opportunistically-breeding and monogamous songbird, the zebra finch. Horm Behav 63:462-474.

Schlinger BA, and London SE. 2006. Neurosteroids and the songbird model system. J Exp Zool A Comp Exp Biol 305:743-748.

Schlinger BA, and Remage-Healey L. 2012. Neurosteroidogenesis: insights from studies of songbirds. $J$ Neuroendocrinol 24:16-21.

Singh TD, Heinrich JE, Wissman AM, Brenowitz EA, Nordeen EJ, and Nordeen KW. 2003. Seasonal regulation of NMDA receptor NR2B mRNA in the adult canary song system. J Neurobiol 54:593603.

Sizemore M, and Perkel DJ. 2011. Premotor synaptic plasticity limited to the critical period for song learning. Proc Natl Acad Sci U S A 108:17492-17497.

Sober SJ, Wohlgemuth MJ, and Brainard MS. 2008. Central contributions to acoustic variation in birdsong. J Neurosci 28:10370-10379.

Spiro JE, Dalva MB, and Mooney R. 1999. Long-range inhibition within the zebra finch song nucleus RA can coordinate the firing of multiple projection neurons. J Neurophysiol 81:3007-3020. 

measurement of song similarity. Anim Behav 59:1167-1176. regulate naturally-occurring neurodegeneration. Dev Growth Differ 53:213-224. song control system. Proc Natl Acad Sci U S A 104:15520-15525. 283. 4770. 20:854-861. Evol 44:265-278.

Wacker DW, Wingfield JC, Davis JE, and Meddle SL. 2010. Seasonal changes in aromatase and 3835. 338:225-241. adult male zebra finches. Horm Behav 44:402-412.

Tables

Table 1 The electrophysiological properties of RA PNs

Tchernichovski O, Nottebohm F, Ho CE, Pesaran B, and Mitra PP. 2000. A procedure for an automated

Thompson CK. 2011. Cell death and the song control system: a model for how sex steroid hormones

Thompson CK, Bentley GE, and Brenowitz EA. 2007. Rapid seasonal-like regression of the adult avian

Thompson CK, and Brenowitz EA. 2005. Seasonal change in neuron size and spacing but not neuronal recruitment in a basal ganglia nucleus in the avian song control system. J Comp Neurol 481:276model of neurodegeneration in the adult avian song control system. J Comp Neurol 518:4760-

Tramontin AD, Hartman VN, and Brenowitz EA. 2000. Breeding conditions induce rapid and sequential growth in adult avian song control circuits: a model of seasonal plasticity in the brain. $J$ Neurosci

Vicario DS. 1994. Motor mechanisms relevant to auditory-vocal interactions in songbirds. Brain Behav androgen receptor, but not estrogen receptor mRNA expression in the brain of the free-living male song sparrow, Melospiza melodia morphna. The Journal of Comparative Neurology 518:3819-

Wild JM. 1993. Descending projections of the songbird nucleus robustus archistriatalis. J Comp Neurol

Williams H, Connor DM, and Hill JW. 2003. Testosterone decreases the potential for song plasticity in

Xie F, London SE, Southey BR, Annangudi SP, Amare A, Rodriguez-Zas SL, Clayton DF, and Sweedler JV. 2010. The zebra finch neuropeptidome: prediction, detection and expression. BMC Biol 8:28. Yu AC, and Margoliash D. 1996. Temporal hierarchical control of singing in birds. Science 273:1871-1875. 


\begin{tabular}{|c|c|c|c|}
\hline Spontaneous firing rate & $8.13 \pm 1.00(\mathrm{n}=21)$ & $12.49 \pm 1.17 * *(\mathrm{n}=23)$ & $11.32 \pm 0.74 * *(\mathrm{n}=10)$ \\
\hline \multicolumn{4}{|l|}{ (Hz) (cell-attached) } \\
\hline Resting membrane & $-65.13 \pm 1.22(n=6)$ & $-65.37 \pm 1.20(\mathrm{n}=7)$ & $-65.32 \pm 1.27(n=2)$ \\
\hline \multicolumn{4}{|l|}{ potential $(\mathrm{mV})$} \\
\hline Spontaneous firing rate & $6.58 \pm 0.89(n=15)$ & $10.53 \pm 1.23 *(n=16)$ & $10.97 \pm 1.26^{* *}(\mathrm{n}=8)$ \\
\hline \multicolumn{4}{|l|}{ (Hz) (Whole-cell) } \\
\hline Membrane time & $25.44 \pm 3.58(n=16)$ & $43.98 \pm 4.42 * *(n=16)$ & $46.28 \pm 4.46^{* *}(\mathrm{n}=8)$ \\
\hline \multicolumn{4}{|l|}{ constant (ms) } \\
\hline Input resistance $(\mathrm{M} \Omega)$ & $197.75 \pm 10.25(\mathrm{n}=16)$ & $228.11 \pm 14.58(n=17)$ & $226.98 \pm 17.33(\mathrm{n}=8)$ \\
\hline Capacitance (pF) & $126.65 \pm 14.71(\mathrm{n}=16)$ & $194.08 \pm 20.97 *(\mathrm{n}=16)$ & $201.49 \pm 21.88 * *(\mathrm{n}=8)$ \\
\hline FI slope (Hz/pA) & $0.186 \pm 0.014(\mathrm{n}=15)$ & $0.296 \pm 0.017^{* *}(\mathrm{n}=13)$ & $0.289 \pm 0.016^{* *}(\mathrm{n}=6)$ \\
\hline AP threshold (mV) & $-50.12 \pm 1.73(n=15)$ & $-49.59 \pm 1.74(n=16)$ & $-50.14 \pm 1.63(\mathrm{n}=8)$ \\
\hline AHP peak amplitude & $-17.30 \pm 1.16(n=15)$ & $-17.57 \pm 1.64(\mathrm{n}=16)$ & $-16.05 \pm 1.70(n=8)$ \\
\hline \multicolumn{4}{|l|}{$(\mathrm{mV})$} \\
\hline AHP time to peak (ms) & $21.38 \pm 1.53(\mathrm{n}=15)$ & $15.44 \pm 1.85^{* *}(\mathrm{n}=16)$ & $15.03 \pm 2.03 * *(\mathrm{n}=8)$ \\
\hline Half-width (ms) & $1.10 \pm 0.10(\mathrm{n}=15)$ & $1.26 \pm 0.34(\mathrm{n}=16)$ & $0.99 \pm 0.13(\mathrm{n}=8)$ \\
\hline Peak amplitude (mV) & $42.32 \pm 2.44(n=15)$ & $49.17 \pm 2.69(\mathrm{n}=16)$ & $48.99 \pm 2.50(n=8)$ \\
\hline
\end{tabular}

406 Numbers in parentheses indicate sample size. $* P<0.05 ; * * P<0.01$. 
Figure 1 Song sonograms and entropy curves (white line) of castration and sham groups in

411 operation and the 30th day after castration, respectively. $\mathbf{B}_{1}, \mathbf{B}_{2}$. The motifs of two birds in the

412 sham group at "pre" operation and the 30th day after sham operation, respectively. When white

413 line became lower, the entropy of syllable was smaller.

415 Figure 2 The entropy of syllable and \% similarity of motif in castration, control, and sham groups. A. Castration group increased the entropy of syllables. Control and sham groups did not change. B. Castration group exhibited decreased \% similarity of motif. Control and sham groups 418 showed no change.

Figure 3 The spontaneous firing of RA PNs in the cell-attached and whole-cell

423 Example traces of spontaneous firing in RA PNs of the castration and control groups,

424 respectively. F. Castration significantly decreased spontaneous firing rates.

425

426 Figure 4 The evoked firing of RA PNs in the whole-cell configuration. A, B. Example traces

427 of AP firing in RA PNs of the castration and control groups in response to injecting a current of

$428100 \mathrm{pA}$ for $500 \mathrm{~ms}$, respectively. C. Castration significantly decreased the number of evoked 
429 firing when injecting a current of $100 \mathrm{pA}$ for $500 \mathrm{~ms}$. D. F-I curve of the castration and control

430 groups. The slope of the F-I curve in the castration group was lower than that of the control

431 group.

432

433 Figure 5 The differences in membrane time constant, capacitance and AHP time to peak

434 between the castration and control groups. A. Castration decreased the membrane time

435 constant. B. Castration decreased the membrane capacitance. C. Example traces of AP in the

436 castration and control groups, showing differences in the AHP time to peak. D. Castration

437 prolonged the AHP time to peak. 


\section{Figure 1}

Song sonograms and entropy curves (white line) of castration and sham groups in adult male zebra finches.

$\mathrm{A} 1, \mathrm{A2}$. The motifs of two birds in the castration group at "pre" operation and the 30th day after castration, respectively. B1,B2. The motifs of two birds in the sham group at "pre" operation and the 30th day after sham operation, respectively. When white line became lower, the entropy of syllable was smaller. 
$\mathbf{A}_{1}$

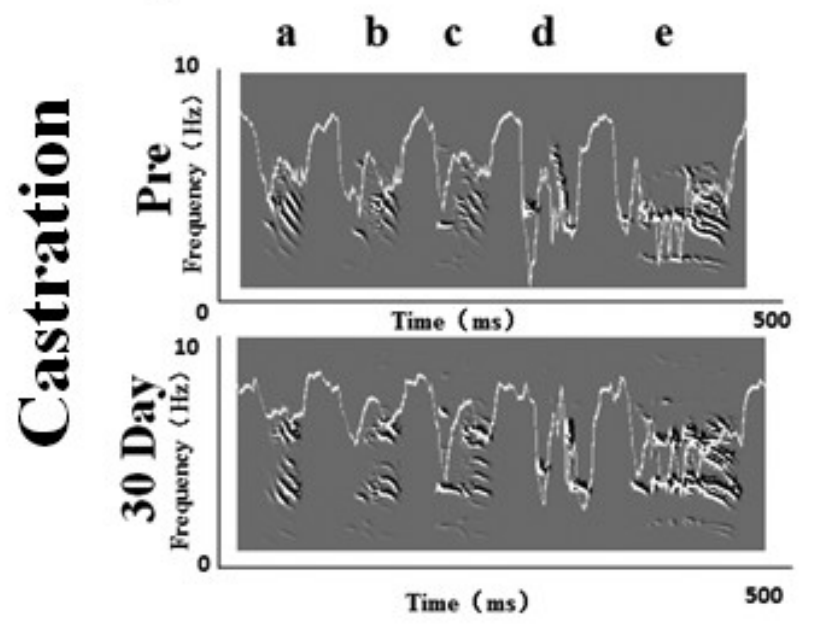

$\mathbf{A}_{2}$

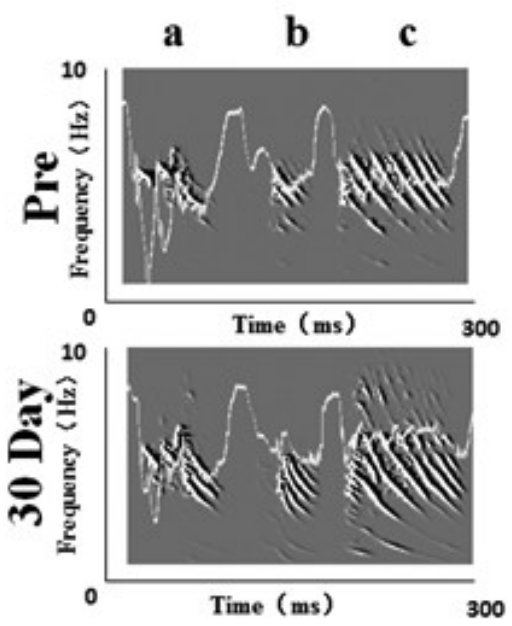

$\mathbf{B}_{1}$

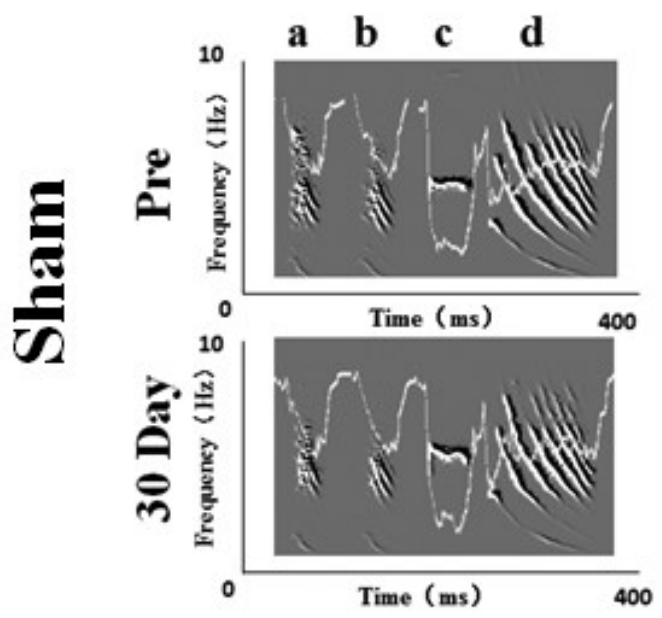

$\mathbf{B}_{2}$

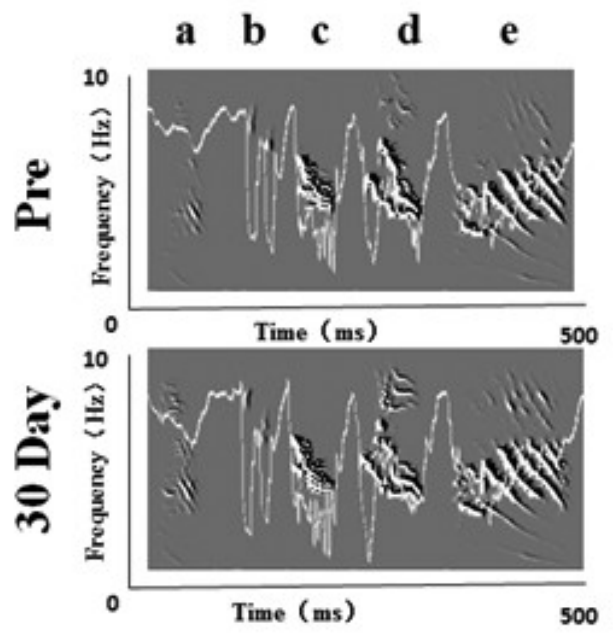




\section{Figure 2}

The entropy of syllable and \% similarity of motif in castration, control, and sham groups.

A. Castration group increased the entropy of syllables. Control and sham groups did not change. B. Castration group exhibited decreased \% similarity of motif. Control and sham groups showed no change.
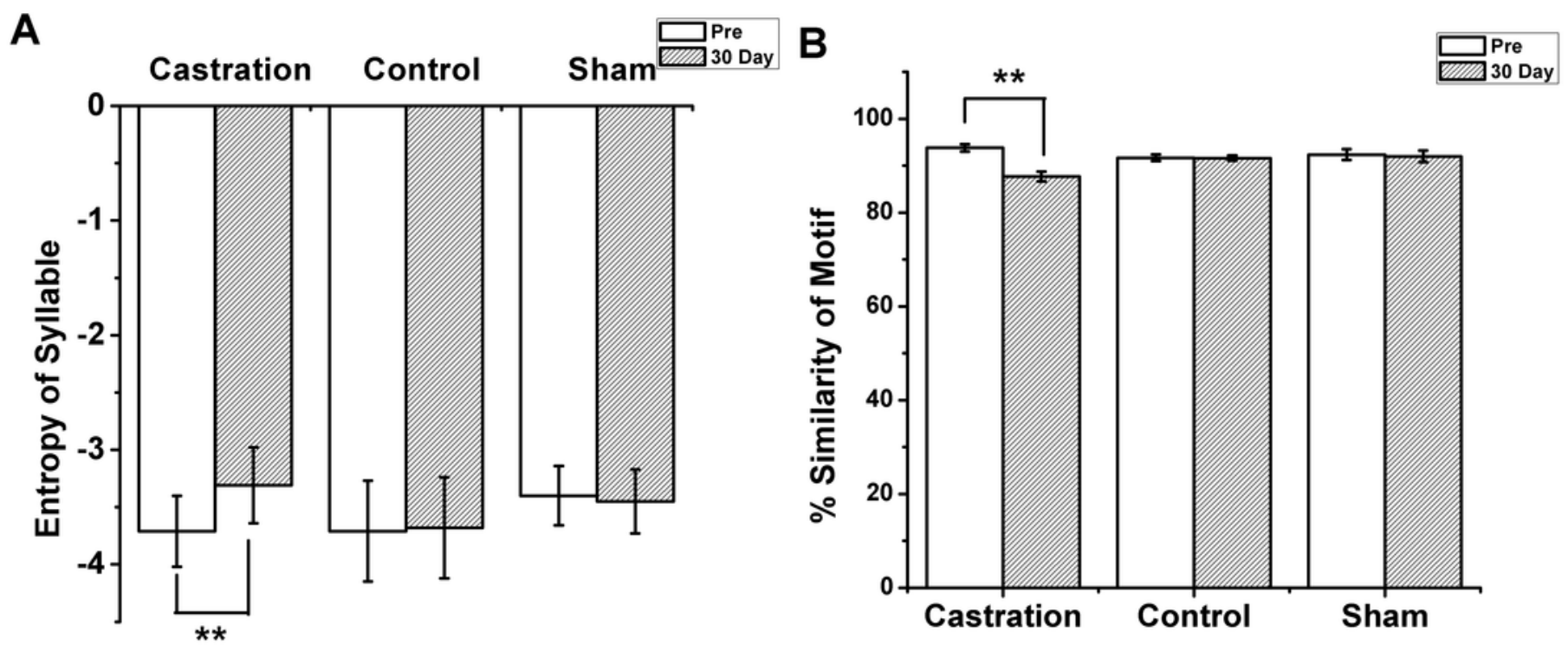


\section{Figure 3}

The spontaneous firing of RA PNs in the cell-attached and whole-cell configuration.

A, B. Example traces of spontaneous firing in RA PNs of the castration and control groups, respectively. C. Castration significantly decreased spontaneous firing rates. D, E. Example traces of spontaneous firing in RA PNs of the castration and control groups, respectively. F. Castration significantly decreased spontaneous firing rates.

\section{Cell-attached}

A

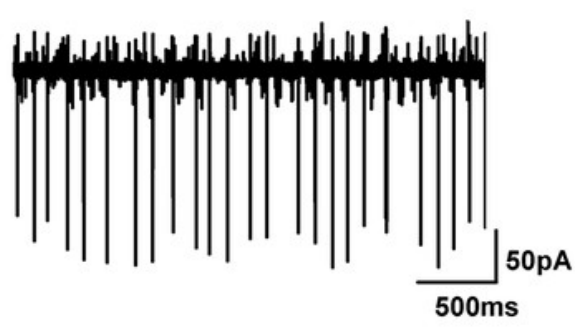

B

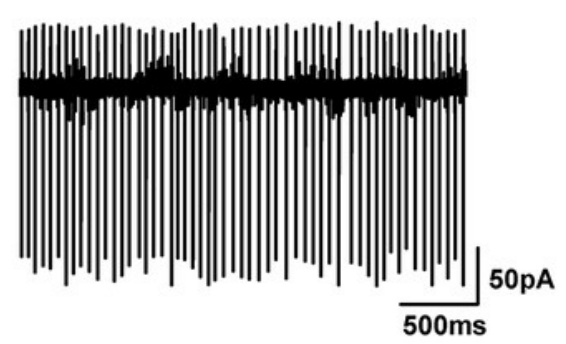

C

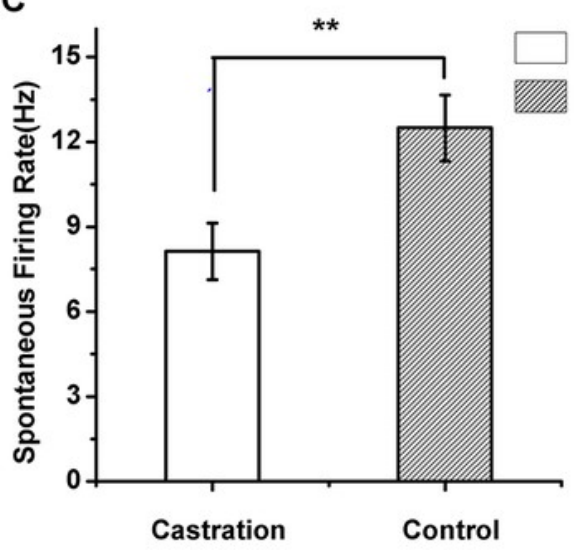

Whole-cell

D

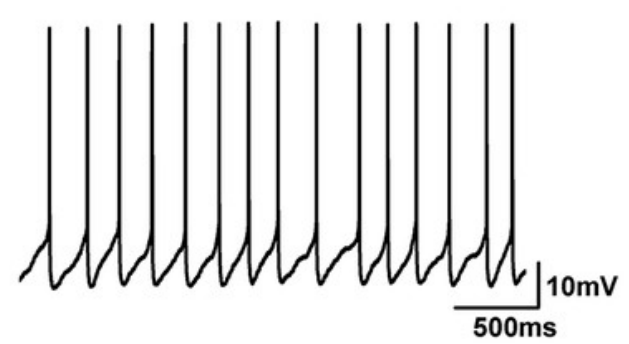

E

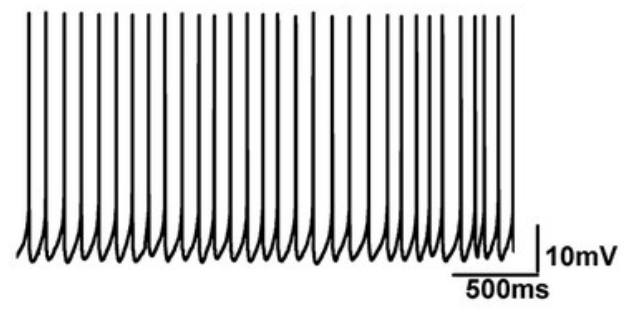

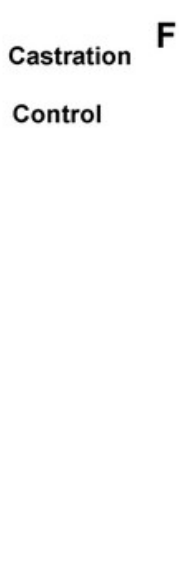

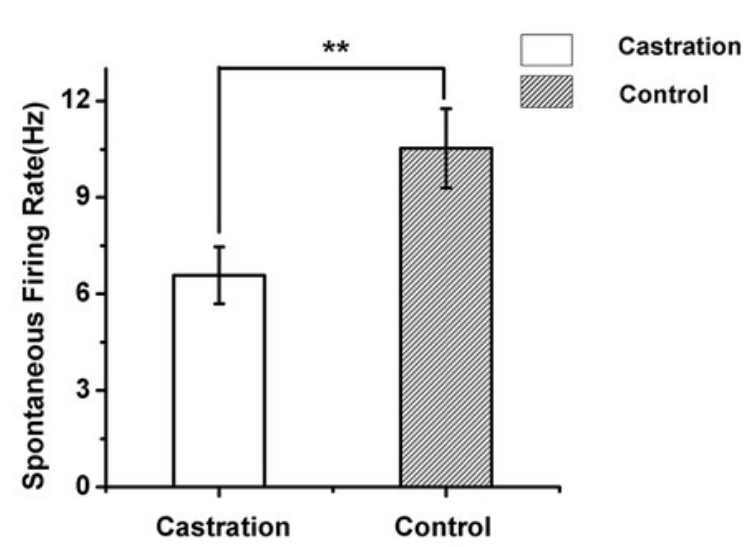




\section{Figure 4}

The evoked firing of RA PNs in the whole-cell configuration.

A, B. Example traces of AP firing in RA PNs of the castration and control groups in response to injecting a current of $100 \mathrm{pA}$ for $500 \mathrm{~ms}$, respectively. C. Castration significantly decreased the number of evoked firing when injecting a current of $100 \mathrm{pA}$ for $500 \mathrm{~ms}$. D. F-I curve of the castration and control groups. The slope of the F-I curve in the castration group was lower than that of the control group.
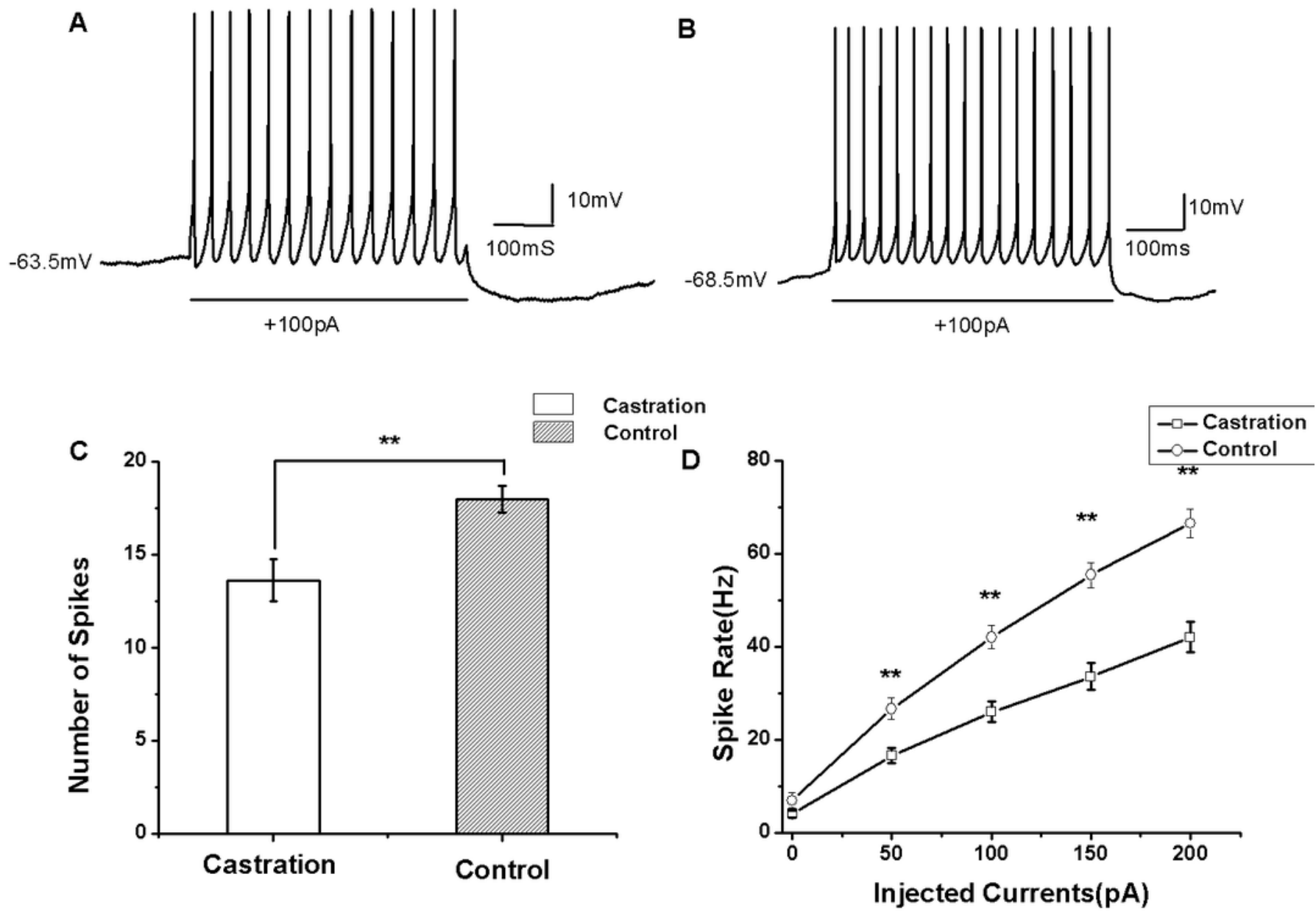


\section{Table 1 (on next page)}

Table 1

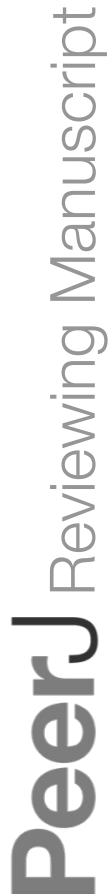


Table 1 The electrophysiological properties of RA PNs

\begin{tabular}{|c|c|c|c|}
\hline Property & Castration & Control & Sham \\
\hline Spontaneous firing rate & $8.13 \pm 1.00(n=21)$ & $12.49 \pm 1.17^{* *}(\mathrm{n}=23)$ & $11.32 \pm 0.74 * *(\mathrm{n}=10)$ \\
\hline \multicolumn{4}{|l|}{ (Hz) (cell-attached) } \\
\hline Resting membrane & $-65.13 \pm 1.22(\mathrm{n}=6)$ & $-65.37 \pm 1.20(\mathrm{n}=7)$ & $-65.32 \pm 1.27(\mathrm{n}=2)$ \\
\hline \multicolumn{4}{|l|}{ potential (mV) } \\
\hline Spontaneous firing rate & $6.58 \pm 0.89(n=15)$ & $10.53 \pm 1.23 *(\mathrm{n}=16)$ & $10.97 \pm 1.26^{* *}(\mathrm{n}=8)$ \\
\hline \multicolumn{4}{|l|}{ (Hz) (Whole-cell) } \\
\hline Membrane time & $25.44 \pm 3.58(\mathrm{n}=16)$ & $43.98 \pm 4.42 * *(\mathrm{n}=16)$ & $46.28 \pm 4.46^{* *}(\mathrm{n}=8)$ \\
\hline \multicolumn{4}{|l|}{ constant (ms) } \\
\hline Input resistance $(\mathrm{M} \Omega)$ & $197.75 \pm 10.25(\mathrm{n}=16)$ & $228.11 \pm 14.58(\mathrm{n}=17)$ & $226.98 \pm 17.33(n=8)$ \\
\hline Capacitance (pF) & $126.65 \pm 14.71(\mathrm{n}=16)$ & $194.08 \pm 20.97 *(n=16)$ & $201.49 \pm 21.88^{* *}(\mathrm{n}=8)$ \\
\hline FI slope (Hz/pA) & $0.186 \pm 0.014(\mathrm{n}=15)$ & $0.296 \pm 0.017 * *(\mathrm{n}=13)$ & $0.289 \pm 0.016^{* *}(\mathrm{n}=6)$ \\
\hline AP threshold (mV) & $-50.12 \pm 1.73(n=15)$ & $-49.59 \pm 1.74(n=16)$ & $-50.14 \pm 1.63(n=8)$ \\
\hline AHP peak amplitude & $-17.30 \pm 1.16(\mathrm{n}=15)$ & $-17.57 \pm 1.64(\mathrm{n}=16)$ & $-16.05 \pm 1.70(\mathrm{n}=8)$ \\
\hline \multicolumn{4}{|l|}{$(\mathrm{mV})$} \\
\hline AHP time to peak (ms) & $21.38 \pm 1.53(\mathrm{n}=15)$ & $15.44 \pm 1.85^{* *}(\mathrm{n}=16)$ & $15.03 \pm 2.03 * *(\mathrm{n}=8)$ \\
\hline Half-width (ms) & $1.10 \pm 0.10(\mathrm{n}=15)$ & $1.26 \pm 0.34(\mathrm{n}=16)$ & $0.99 \pm 0.13(\mathrm{n}=8)$ \\
\hline Peak amplitude (mV) & $42.32 \pm 2.44(\mathrm{n}=15)$ & $49.17 \pm 2.69(\mathrm{n}=16)$ & $48.99 \pm 2.50(n=8)$ \\
\hline
\end{tabular}

Numbers in parentheses indicate sample size. ${ }^{*} P<0.05 ; * * P<0.01$. 


\section{Figure 5}

The differences in membrane time constant, capacitance and AHP time to peak between the castration and control groups.

A. Castration decreased the membrane time constant. B. Castration decreased the membrane capacitance. C. Example traces of AP in the castration and control groups, showing differences in the AHP time to peak. D. Castration prolonged the AHP time to peak.
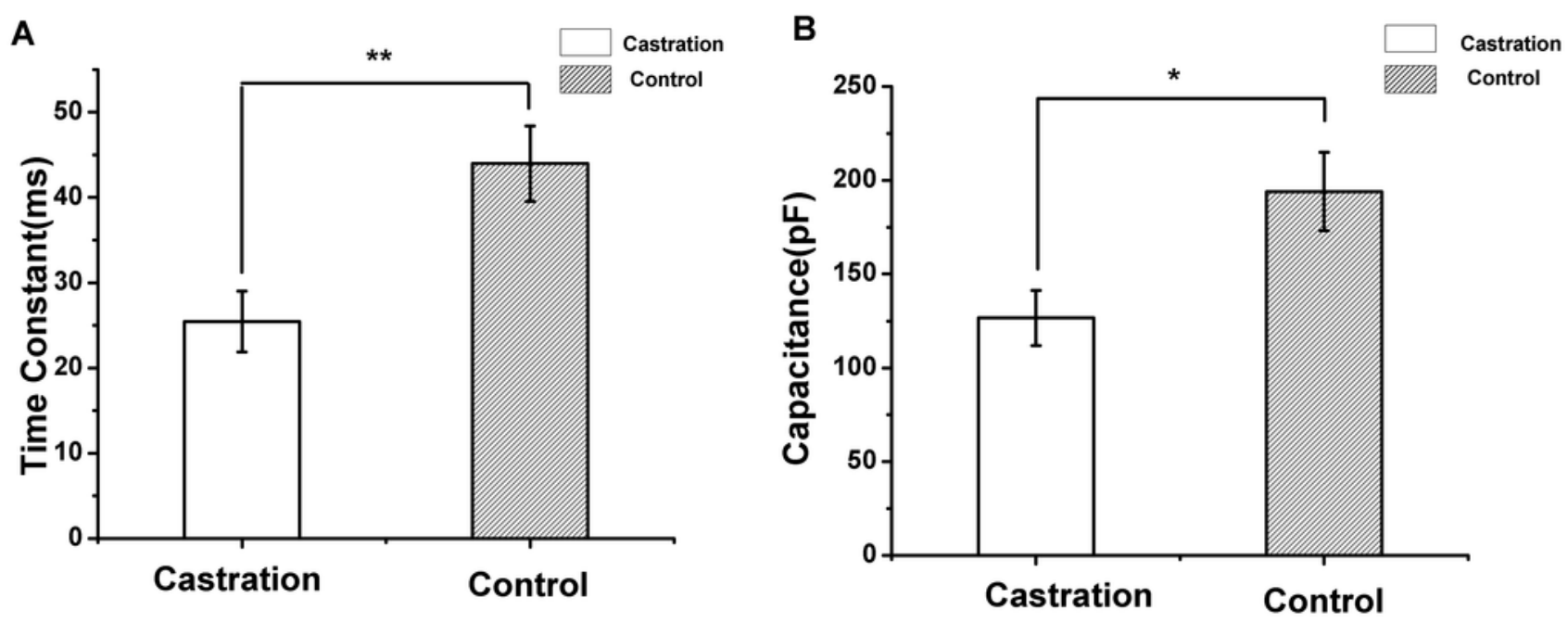

C

D
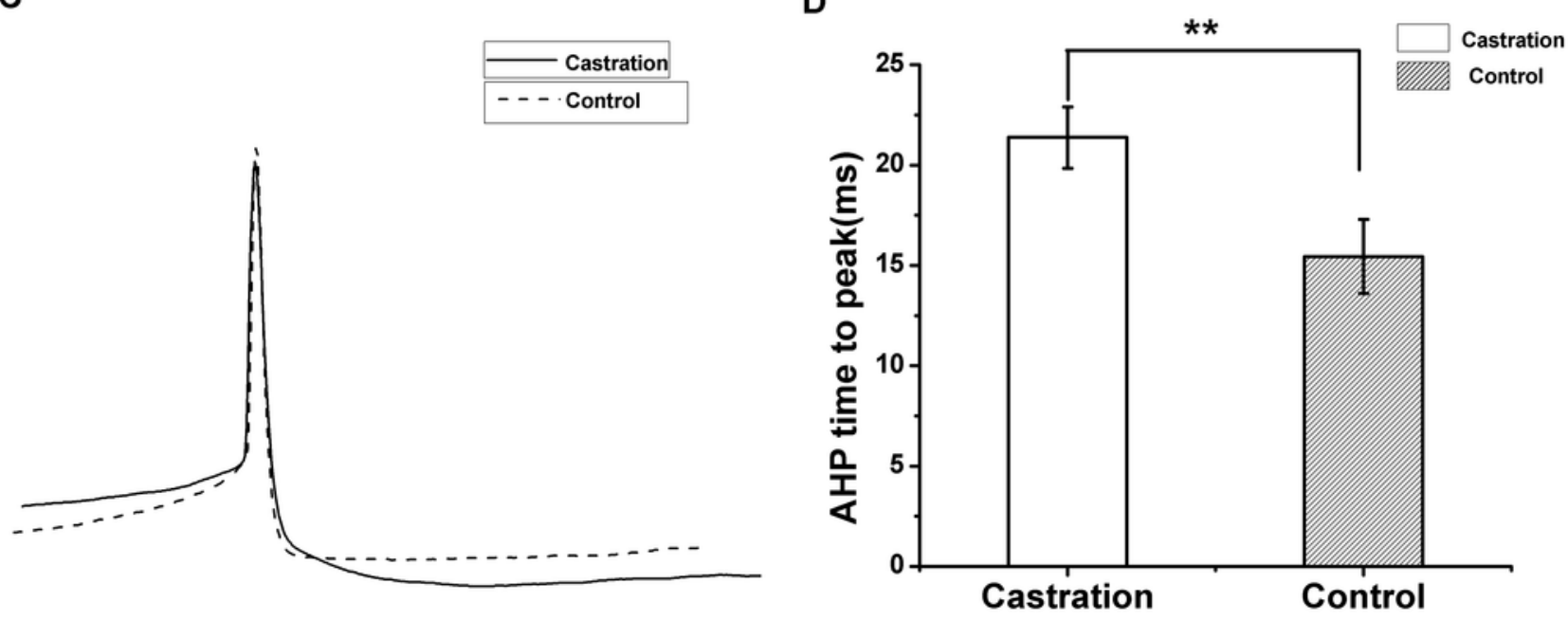